\title{
Анализ поведения неравновесных полупроводниковых структур и СВЧ транзисторов в момент и после импульсного $\gamma$ - и $\gamma$-нейтронного облучения
}

\author{
(C) М.М. Венедиктов ${ }^{1}$, Е.А. Тарасова ${ }^{2}$, А.Д. Боженькина ${ }^{2}$, С.В. Оболенский ${ }^{2}$, В.В. Елесин ${ }^{3}$, \\ Г.В. Чуков ${ }^{3}$, И.О. Метелкин ${ }^{3}$, М.А. Кревский ${ }^{4}$, Д.И. Дюков ${ }^{4}$, А.Г. Ферелов ${ }^{4}$ \\ ${ }^{1}$ ФНПЦ „НИИИС им. Ю.Е. Седакова“, \\ 603137 Нижний Новгород, Россия \\ ${ }^{2}$ Нижегородский государственный университет им. Н.И. Лобачевского, \\ 603600 Нижний Новгород, Россия \\ ${ }^{3}$ Национальный исследовательский ядерный университет „МИФИ“, \\ 115409 Москва, Россия \\ ${ }^{4}$ ОАО „НПП Салют“, \\ 603152 Нижний Новгород, Россия \\ E-mail: thelen@yandex.ru, obolensk@rf.unn.ru
}

(Получена 25 апреля 2018 г. Принята к печати 7 мая 2018 г.)

\begin{abstract}
Проведен анализ влияния неравновесных процессов в полупроводниковых структурах при радиационном воздействии на характеристики структур и СВЧ-транзисторов на их основе. Особое внимание обращено на сопоставление параметров опытных (экспериментальных) и серийных структур и транзисторов на их основе до и после $\gamma$-нейтронного облучения.
\end{abstract}

DOI: $10.21883 /$ FTP.2018.12.46749.28

\section{1. Введение}

На ранних стадиях разработки перспективных полупроводниковых структур и приборов на их основе часто возникают сложности с изготовлением структур такого качества, чтобы внешние дестабилизирующие факторы, например радиационное воздействие, не приводили к резким изменениям параметров структур, связанным с внутренней перестройкой их примесного дефектного состава. Это может сильно сказываться на уровне радиационной стойкости приборов. Важным фактором здесь является неравновесность распределений дефектов и примесей на границах слоев структур, которые изменяются уже при незначительном уровне радиационного воздействия. Это вызывает разброс результатов экспериментов и затрудняет их трактовку [1]. Так как радиационные и технологические дефекты существенно влияют на шумы СВЧ полевых транзисторов [2,3], то важно исследовать не только параметры полупроводниковых структур, но и измерять коэффициенты усиления и шума транзисторов до и после воздействия в приемлемой по объему выборке образцов. В связи с большим объемом требуемых экспериментов бывает затруднительно получить такую выборку, чтобы был возможен анализ статистического распределения параметров. Последнее важно именно при проведении исследований нестандартного поведения образцов.

В данной работе на основе большого статистического материала сопоставлено поведение равновесных и неравновесных полупроводниковых структур, а также СВЧ транзисторов на их основе при $\gamma$ - и $\gamma$-нейтронном облучении. Указанное имеет важное значение для трактовки результатов испытаний СВЧ интегральных схем и приборов на радиационную стойкость.

\section{2. Объекты исследований}

Ранее авторами проводились теоретические и экспериментальные исследования вольт-амперных (BАХ), вольт-фарадных (ВФХ) характеристик полупроводниковых структур и СВЧ коэффициентов усиления и шума классических GaAs полевых транзисторов Шоттки (ПТШ), а также транзисторов с двумерным электронным газом (HEMT) на InGaAs/AlGaAs и GaN/AlGaN структурах как отечественного, так и зарубежного производства, [4-7] (табл. 1). Следует отметить, что в отличие от кремниевых МДП-транзисторов и интегральных схем на их основе, где основным поражающим фактором является $\gamma$-излучение, ионизирующее полупроводниковые структуры и формирующее связанные положительные заряды в диэлектрических слоях, для СВЧ транзисторов основным поражающим фактором являются нейтронное излучение, формирующее скопления радиационных дефектов, а также $\gamma$-излучение ионизующее полупроводник.

Из работ $[4,5]$ известно, что указанные в табл. 1 структуры и транзисторы на их основе имеют высокую радиационную стойкость и выдерживают $\gamma$-нейтронное облучение с флюенсом нейтронов $10^{14}-10^{15} \mathrm{~cm}^{-2}$ и дозой $\gamma$-квантов $10^{6}-10^{7}$ рад. Это подтверждено и результатами работ авторов [3-12]. Однако за рамками предыдущих работ остался большой объем данных по радиационной стойкости пробных образцов перспективных структур и СВЧ транзисторов, которые объединяло общее нестандартное поведение при слабом импульсном $\left(\tau_{\mathrm{p}} \sim 1 \mathrm{Mc}\right)$ облучении $\gamma$-нейтронами спектра деления колоколообразного типа $(0.1-3 \mathrm{MэВ,} \mathrm{максимум} \mathrm{-}$ $1 \mathrm{MэB})$, флюенсом $10^{12}-10^{14} \mathrm{~cm}^{-2}$ и сопутствующей до- 
Таблица 1. Основные параметры СВЧ полевых транзисторов Шоттки и СВЧ полевых транзисторов с каналом на основе слоя с квантовой ямой, содержащей двумерный электронный газ (НЕМТ)*

\begin{tabular}{|c|c|c|c|c|c|c|c|c|c|}
\hline $\begin{array}{c}\text { № } \\
\text { п. п. }\end{array}$ & $\begin{array}{c}\text { Тип } \\
\text { прибора }\end{array}$ & $\begin{array}{c}\text { Тип и особенности } \\
\text { полупроводниковой } \\
\text { структуры }\end{array}$ & $\begin{array}{c}\text { Длина } \\
\text { затвора } \\
\left(L_{g}\right), \text { мкм }\end{array}$ & $\begin{array}{c}\text { Ширина } \\
\text { затвора } \\
(W), \text { мкм }\end{array}$ & $\begin{array}{c}\text { Количество } \\
\text { образцов }\end{array}$ & $\begin{array}{c}\text { Время } \\
\text { потери } \\
\text { работоспо- } \\
\text { собности } \\
\text { после } \\
\text { импульса } \\
\gamma \text {-излучения, } \\
\text { мкс }\end{array}$ & \begin{tabular}{|c|} 
Время \\
потери \\
работоспо- \\
собности \\
после \\
импульса \\
нейтронного \\
облучения, \\
мс
\end{tabular} & $\begin{array}{c}\text { Относительное } \\
\text { изменение } \\
\text { коэффициента } \\
\text { передачи } \\
\text { до и после } \\
\text { облучения } \\
\text { нейтронами } \\
\text { с флюенсом } \\
2 \cdot 10^{14} \mathrm{~cm}^{-2}, \%\end{array}$ & $\begin{array}{c}\text { Отношение } \\
\text { коэффициента } \\
\text { шума } \\
\text { до и после } \\
\text { облучения } \\
\text { нейтронами } \\
\text { с флюенсом } \\
2 \cdot 10^{14} \mathrm{~cm}^{-2}, \%\end{array}$ \\
\hline 1 & ПТШ & $\begin{array}{c}n^{-}-n-n^{+}-\mathrm{GaAs} \\
\mathrm{C}, \mathrm{O}, \text { ГФЭ }\end{array}$ & 1.2 & 280 & 12 & 8 & - & $10-15 \%$ & $-12-20 \%$ \\
\hline 2 & ПТШ & $\begin{array}{c}n^{-}-n-n^{+}-\mathrm{GaAs} \\
\mathrm{C}, \mathrm{O}, \text { ГФЭ }\end{array}$ & 0.4 & 300 & 12 & 12 & - & $10-15 \%$ & $-12-20 \%$ \\
\hline 3 & ПТШ & $\begin{array}{c}n^{-}-n-n^{+}-\mathrm{GaAs}, \\
\mathrm{C}, \mathrm{O}, \Gamma \Phi \ni\end{array}$ & 0.25 & 100 & 25 & 9 & 5 & $6.5-7.5 \%$ & $-40 \%$ \\
\hline 4 & ПТШ & $\begin{array}{c}n^{-}-n-n^{+}-\mathrm{GaAs} \\
\Pi, \mathrm{O}, \Gamma Ф Э\end{array}$ & 0.1 & 50 & 16 & 16 & 27 & $40-55 \%$ & $-10 \%$ \\
\hline 5 & ПТШ & $\begin{array}{c}n^{-}-n-n^{+}-\mathrm{GaAs} \\
\text { П, О, МПЭ }\end{array}$ & 0.1 & 50 & 16 & 3 & 2 & $\begin{array}{c}-18-21 \% \\
\text { улучшение }\end{array}$ & $\begin{array}{c}+5 \% \\
\text { улучшение }\end{array}$ \\
\hline 6 & HEMT & $\begin{array}{c}\text { InGaAs/AlGaAs, } \\
\text { C, O, МПЭ }\end{array}$ & 0.25 & 100 & 24 & 12 & 6 & $4-8 \%$ & $-5-10 \%$ \\
\hline 7 & HEMT & $\begin{array}{c}\mathrm{InGaAs} / \mathrm{AlGaAs}, \\
П, \mathrm{O}, Г Ф Э\end{array}$ & 0.25 & 100 & 24 & 16 & 7 & $\begin{array}{c}-15-20 \% \\
\text { улучшение }\end{array}$ & $\begin{array}{c}+5-10 \% \\
\text { улучшение }\end{array}$ \\
\hline 8 & HEMT & $\begin{array}{c}\text { InGaAs/AlGaAs, } \\
\text { C, 3, МПЭ }\end{array}$ & 0.15 & 50 & 5 & 9 & 9 & $4-8 \%$ & $-5-10 \%$ \\
\hline 9 & HEMT & $\begin{array}{c}\mathrm{GaN} / \mathrm{AlGaN} \\
\text { на } \mathrm{Al}_{2} \mathrm{O}_{3} \\
\Pi, \text { О, ГФЭ }\end{array}$ & 0.5 & 100 & 5 & 24 & 10 & $<4 \%$ & - \\
\hline 10 & HEMT & $\begin{array}{c}\mathrm{GaN} / \mathrm{AlGaN} \\
\text { на } \mathrm{SiC} \\
\mathrm{C}, 3, \text { ГФЭ }\end{array}$ & 0.5 & 300 & 3 & 14 & 4 & $<4 \%$ & - \\
\hline
\end{tabular}

Примечание. * GaAs-структуры изготавливались на $i$-GaAs, GaN-структуры — на сапфире и карбиде кремния. С - структура серийного производства; П - пробная структура; О - структура отечественного производства, 3 - структура отечественного производства, ГФЭ структура изготовлена методом газофазной эпитаксии, МПЭ - структура изготовлена методом молекулярно-пучковой эпитаксии.

зой $\gamma$-квантов $10^{3}-10^{5}$ рад. Кроме того указанные структуры также нестандартным образом реагировали на импульсное $\gamma$-облучение (средняя энергия квантов 1 МэВ) с мощностью дозы $10^{10}-10^{12} \mathrm{P} / \mathrm{c}$ и дозой $10^{3}-10^{5} \mathrm{P}$ за импульс.

Цель данной работы заключалась в выявлении общих особенностей в поведении подобного рода структур и транзисторов, создании методов обработки результатов экспериментов при условии малого (10-20шт.) объема экспериментальной выборки, не позволяющего восстановить форму функции распределения параметров образцов в полном объеме. Для обработки результатов использовались численная математическая модель и специальные статистические методы обработки результатов расчетов и экспериментов.

В качестве основного объекта были выбраны классические CВЧ GaAs полевые транзисторы Шоттки, так как объем экспериментальных данных для них был наиболь- шим. С ними сравнивалось поведение других структур и СВЧ полевых транзисторов, перечисленных выше.

\section{3. Математическая модель и методы экспериментальных исследований}

В условиях радиационного воздействия уменьшение размеров структур приводит к принципиальным изменениям физики работы приборов, связанным с тем, что: 1) характерные пространственные масштабы изменения электрического поля сопоставимы с длинами релаксации энергии и импульса электронов и длиной свободного пробега электронов $[1,3] ; 2)$ характерные размеры рабочих областей приборов сравнимы с расстоянием между кластерами радиационных дефектов $[1,8,9]$; 3) характерные размеры рабочих областей приборов сопоставимы с размерами кластера радиационных дефек- 
тов $[8,9]$; 4) характерные размеры двумерного канала НЕМТ сопоставимы с размерами кластеров радиационных дефектов [11,12]; 5) наличие неравновесных распределений технологических и радиационных дефектов обусловливает перестройку примесно-дефектной системы полупроводниковых структур транзисторов [1].

В этом случае анализ радиационной стойкости предполагает использование двумерного приближения и учета ряда новых эффектов, связанных с разогревом электронного газа при радиационном воздействии и рассеянием носителей на технологических и радиационных дефектах. Для анализа радиационного воздействия на субмикронные полупроводниковые приборы использовался квазигидродинамический метод описания движения носителей заряда, система уравнений которого в обобщенном виде имеет вид [6-8]:

$$
\begin{gathered}
\Delta V=\frac{q}{\varepsilon_{s} \varepsilon_{0}}\left(n\left(F_{n}\right)-N_{+}\left(F_{n}\right)+N_{-}\left(F_{n}\right)\right) ; \quad \mathbf{E}=-\nabla V \\
\mathbf{j}_{t}=\mathbf{j}_{n}+\varepsilon_{s} \frac{\partial \mathbf{E}}{\partial t} ; \quad \frac{d m(W) \mathbf{v}\left(F_{n}\right)}{d t}=-q \mathbf{E}-\frac{m(W)}{\tau_{p}\left(F_{n}\right)} \mathbf{v}\left(F_{n}\right) ; \\
\frac{\partial n\left(F_{n}\right)}{\partial t}=\frac{1}{q}\left(\nabla, \mathbf{j}_{n}\right)+G-R ; \\
\frac{\partial\left(W n\left(F_{n}\right)\right)}{\partial t}=\left(\nabla, \mathbf{j}_{W}\right)+\left(\mathbf{j}_{n}, \mathbf{E}\right)+G W_{e}-\frac{n\left(F_{n}\right)\left(W-W_{0}\right)}{\tau_{W}\left(F_{n}\right)} \\
\mathbf{j}_{n}=-q n \mathbf{v}\left(F_{n}\right)+q \nabla\left(D\left(F_{n}\right) n\left(F_{n}\right)\right) ; \\
\mathbf{j}_{W}=-n\left(F_{n}\right) W \mathbf{v}\left(F_{n}\right)+\nabla\left(D\left(F_{n}\right) n\left(F_{n}\right) W\right)
\end{gathered}
$$

где $V$ - потенциал, $n-$ концентрация электронов, $N_{+}, N_{-}$- концентрации положительно и отрицательно заряженных ионов (доноров, акцепторов, радиационных дефектов), $\mathbf{j}_{n}, \mathbf{j}_{t}-$ плотность электронного и полного тока, $\mathbf{j}_{W}$ - плотность потока энергии электронов, $W, W_{0}$ - неравновесная и равновесная энергия электрона соответственно, $\tau_{w}$ - время релаксации энергии, $\tau_{p}$ - время релаксации импульса, $m$ - эффективная масса электрона, $D$ - коэффициент диффузии электронов, $\mathbf{v}$ - дрейфовая скорость электронов, $\mathbf{E}-$ напряженность электрического поля, $\varepsilon_{s}$ - диэлектрическая проницаемость, $F_{n}-$ флюенс нейтронов, $q-$ абсолютная величина заряда электрона, $G$ - коэффициент генерации носителей заряда при воздействии излучения (учитывается только в момент действия излучения), $R$ - коэффициент рекомбинации (учитывается только в момент и непосредственно после действия излучения), $W_{e}-$ средняя энергия генерируемого электрона $[5,8,10]$.

Для моделирования процессов в транзисторах используются граничные условия смешанного типа на границах контактов задаются значения потенциала, концентрации и энергии носителей. При этом значение потенциала могло быть как фиксированным, так и изменяющимся в произвольных пределах при моделировании процессов транспорта носителей в условиях большого сигнала. На контактах значение концентрации задается равным концентрации в контактном слое GaAs, а температура электронного газа - равной комнатной. На остальных поверхностях расчетной области поддерживаются нулевыми градиенты потенциала, концентрации и энергии электронов так, что нулевыми являются значения плотностей тока электронов и потока энергии электронного газа $[5,8,10]$.

Для определения изменения времен релаксации энергии и импульса, средней энергии и дрейфовой скорости электронов, других параметров полупроводникового материала при радиационном воздействии обычно используется метод Монте-Карло [5]. Для учета точечных дефектов необходимо вводить дополнительный механизм [5,8,9] малоуглового рассеяния на основе потенциала взаимодействия Брукса-Херринга. Взаимодействие носителей заряда с кластерами дефектов обычно рассматривается как упругое рассеяние на включениях, окруженных областью пространственного заряда, со случайным угловым распределением. Размер области, блокирующей поток электронов, зависит от энергии налетающего электрона [4].

В ряде структур на основе $\mathrm{GaN}$ наблюдался сдвиг профиля распределения электронов после облучения нейтронами с флюенсом $10^{13}-10^{15} \mathrm{~cm}^{-2}$ [4]. Для анализа полученных результатов были проведены расчеты распределения кластеров радиационных дефектов (КРД) в данной структуре методом Монте-Карло с помощью программы Trim [8]. Результаты расчетов подтвердили, что в подобного типа структурах средний размер кластера радиационных дефектов будет „выкусывать“ область размером 10-25нм, что и будет приводить к сдвигу профиля распределения электронов в структуре [4].

С целью уточнения параметров полупроводниковой структуры транзисторов до, в момент и после радиационного воздействия применялся специальный метод, основанный на одномерной модели Пуассона. Проводился расчет профилей распределения легирующих примесей, радиационных дефектов и электронов по глубине структуры, а также профиль ее зонной диаграммы. Затем проводилось сравнение с экспериментальными ВАХ и ВФХ с последующей коррекцией профиля легирующей примеси и радиационных дефектов, заложенных в модель. Итерации повторялись до тех пор, пока расчет и эксперимент не совпадали с приемлемой точностью. После этого результаты измерения высокочастотных параметров транзисторов в момент и после радиационного воздействия сопоставляли с результатами расчета и определяли погрешность используемой модели. Низкий уровень (10-25\%) погрешности позволил использовать результаты расчетов для трактовки наблюдаемых в эксперименте процессов релаксации параметров полупроводниковых структур и транзисторов на их основе.

Для экспериментальных исследований использовались импульсные и стационарные источники $\gamma$ - и $\gamma$-нейтронного излучения - рентгеновские источники и импульсные ядерные реакторы. Флюенсы нейтронного облучения составляли $10^{12}-10^{15} \mathrm{~cm}^{-2}$, а доза $\gamma$-квантов 
от $10^{3}$ до $10^{7}$ рад. В момент и после радиационного воздействия измерялись ток стока и затвора транзисторов, коэффициенты усиления и шума, выходная мощность полезного сигнала.

\section{4. Сравнение результатов эксперимента и расчета}

Анализ экспериментальных данных, а также результатов аналитического расчета и численного физикотопологического моделирования позволил выявить следующие общие закономерности:

- ионизационная реакция транзистора определяется процессами объемной ионизационной проводимости подложки и буферного слоя между областями стока и истока и соответствующими шинами металлизации;

- долговременная составляющая изменений токов транзисторов связана с наличием в подложке и буферном слое глубоких центров захвата электронов (дырок);

- стационарные изменения параметров транзисторов связаны с накоплением точечных радиационных дефектов и их кластеров, что приводит к снижению концентрации электронов в структурах, уменьшению подвижности и скорости насыщения электронов, ведущие к снижению токов транзисторов, их коэффициента усиления и выходной мощности. Коэффициент шума транзисторов увеличивается. Указанные закономерности физических процессов в общем совпадают с аналогичными заключениями других авторов (см., например, [1]), но есть и отличия, которые будут обсуждаться далее. Рассмотрим указанные процессы более детально.

На рис. 1 приведены результаты расчета ионизационной реакции тока стока полевого транзистора Шоттки при импульсном воздействии радиации при напряжении сток-исток $\left(U_{\mathrm{sd}}\right) 2$ В и напряжении затвор-исток $\left(U_{\mathrm{gs}}\right) 2$ В. Согласно расчету, время восстановления тока существенно зависит от сечения захвата электрона

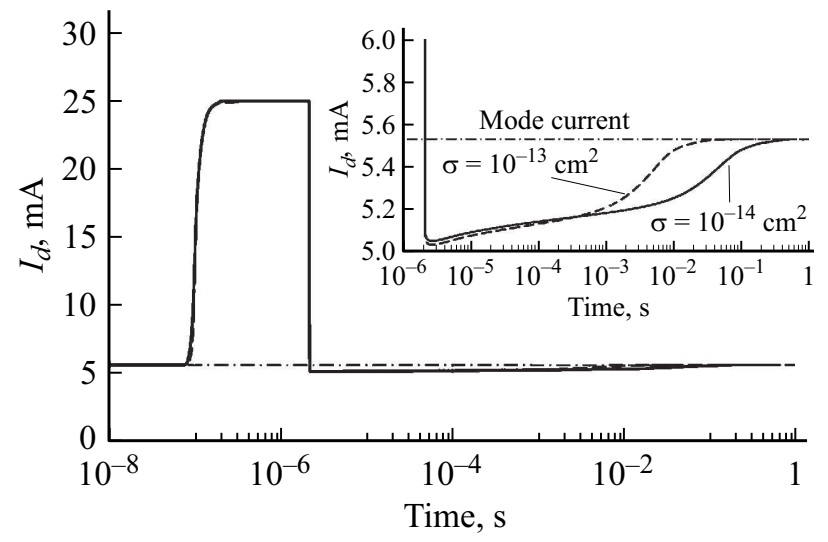

Рис. 1. Расчетная реакция тока стока полевого транзистора Шоттки при импульсном воздействии ИИ $\left(U_{\mathrm{sd}}=0 \mathrm{~B}\right.$, $U_{\mathrm{gs}}=2 \mathrm{~B}, \quad P=4 \cdot 10^{9}$ рад/с), полученная с использованием физико-топологического моделирования. На вставке - область восстановления тока стока при различных сечениях захвата [7]

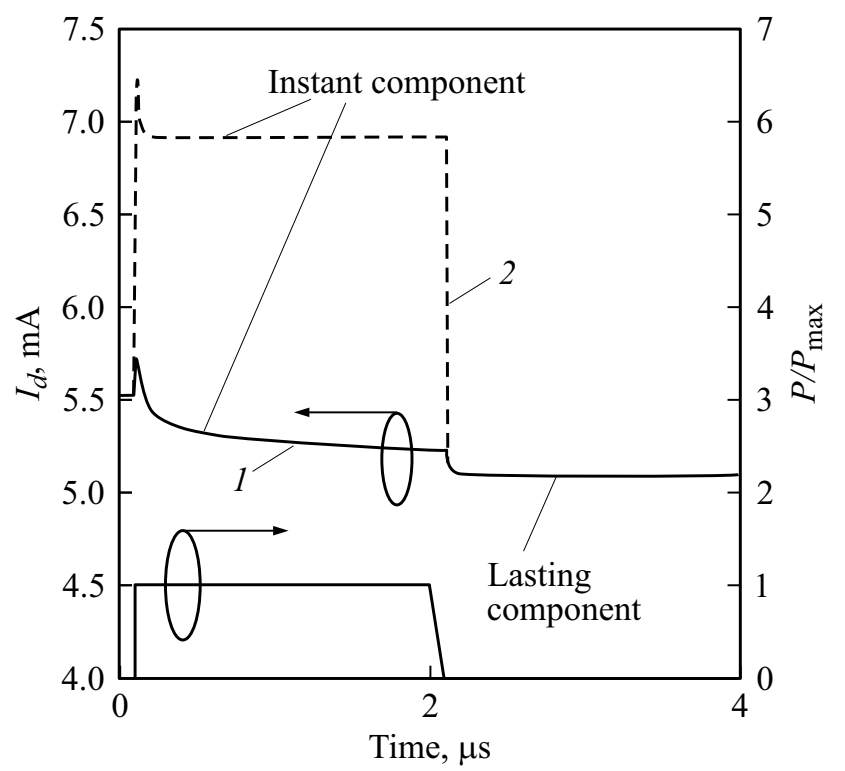

Рис. 2. Зависимость тока стока полевого транзистора Шоттки при $U_{\mathrm{sd}}=0 \mathrm{~B}, U_{\mathrm{gs}}=2 \mathrm{~B}: 1-P=3 \cdot 10^{7} \mathrm{paz} / \mathrm{c}, 2-$ $P=4 \cdot 10^{9}$ рад/с. Данные приведены для структуры из группы 2 табл. 1.

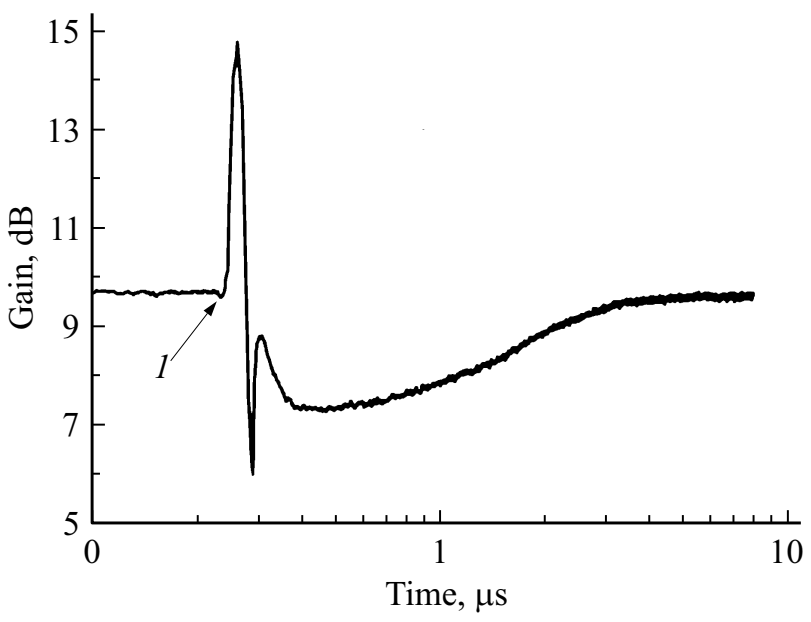

Рис. 3. Экспериментальные осциллограммы зависимости коэффициента усиления полевого транзистора Шоттки от времени при воздействии импульсного $\gamma$-излучения с мощностью дозы $4 \cdot 10^{9}$ рад/с. 1 - момент начала импульса облучения.

ловушкой $(\sigma)$ в подложке или буферном слое. Теоретически показано, что наличие зависимости времени восстановления тока стока от напряжения сток-исток объясняется зависимостью $\sigma$ от электрического поля (эффект Пула-Френкеля) [7].

В результате экспериментальных исследований было установлено, что амплитудно-временны́е характеристики ионизационных реакций тока стока и коэффициента усиления классических GaAs ПТШ при импульсном воздействии $\gamma$-излучения имеют две характерные составляющие (см. рис. 2 и 3): мгновенную, совпадающую по длительности с импульсом радиации, и долговременную - с характерной постоянной времени восстанов- 
ления, находящейся в диапазоне от нескольких единиц микросекунд до десятков миллисекунд.

Экспериментальные и теоретические исследования показали, что общая картина, протекающая во всех типах исследуемых транзисторов в момент и после импульсного $\gamma$-облучения, следующая. Ток стока, выходная мощность сигнала, коэффициент усиления транзисторов в момент нейтронного облучения резко увеличиваются, затем уменьшаются и далее плавно восстанавливаются до значений, меньших, чем до облучения. Аналогично коэффициент шума возрастает, а затем восстанавливается, но до значений, несколько больших, чем до облучения. Характерные времена восстановления параметров транзисторов составляют $\sim 0.1-10$ мс и обусловливаются процессами стабилизации кластеров радиационных дефектов и образованием комплексов точечных дефектов в образцах.

Обсудим это более подробно. Регистрация зависимостей тока транзисторов от времени при воздействии импульса нейтронного излучения (рис. 4) с флюенсом $3 \cdot 10^{14} \mathrm{~cm}^{-2}$ позволила зафиксировать процесс перестройки комплексов радиационных дефектов в миллисекундном диапазоне. Анализ выходных ВАХ транзисторов, снятых через каждые 5 мс после нейтронного импульса, позволил оценить глубину залегания уровней, соответствующих радиационным дефектам в запрещенной зоне. Анализ экспериментальных данных и результаты расчета показали, что происходит перестройка структуры оболочки кластеров радиационных дефектов. Характерное время перестройки составляет 5-15мс, a концентрация точечных радиационных дефектов за это время уменьшается на порядок, что коррелирует с данными [1].

На рис. 5 приведены экспериментальные и расчетные зависимости емкости затвор-исток и крутизны ВАХ полевых транзисторов Шоттки до и после $\gamma$-нейтронного

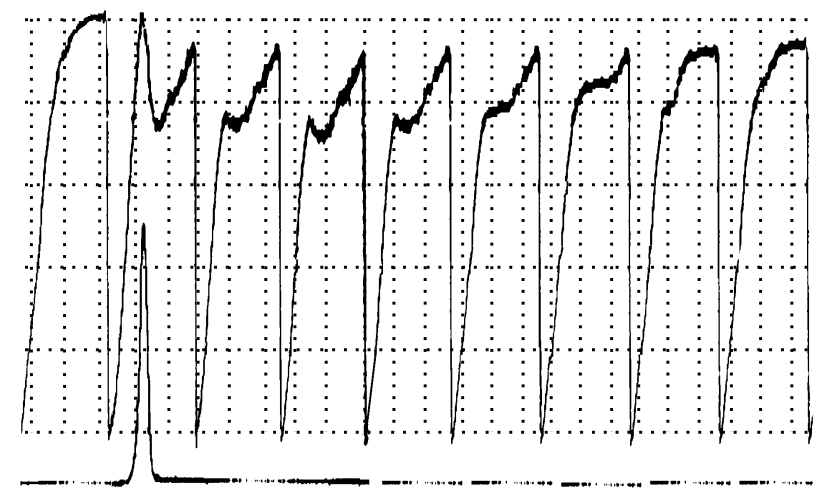

Рис. 4. Релаксация ВАХ субмикронного ПТШ после облучения импульсом нейтронов с флюенсом $3 \cdot 10^{14} \mathrm{~cm}^{-2}$. Верхний луч - напряжение, пропорциональное току стока ПТШ: напряжение затвор-исток $U_{\text {sd }}=-1 \mathrm{~B}$, напряжение на стоке пилообразное $0-5 \mathrm{~B}$, развертка $-2 \mathrm{мc/кл.} \mathrm{Нижний} \mathrm{луч} \mathrm{-}$ сигнал с детектора нейтронного излучения. Данные приведены для структуры из группы 3 табл. 1.

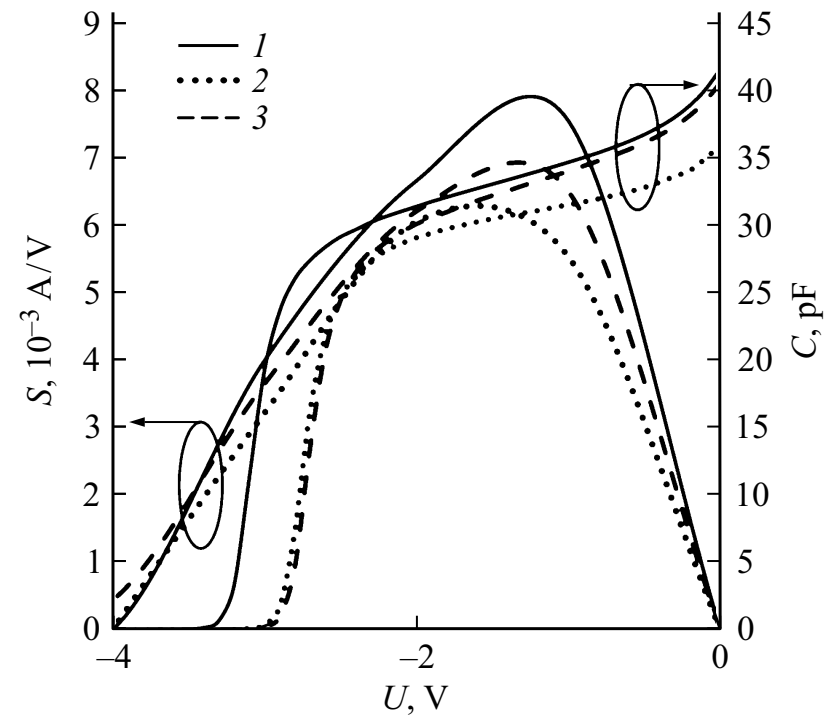

Рис. 5. Вольт-фарадные характеристики GaAs-структуры и крутизна BAX GaAs полевого транзистора Шоттки до и после облучения $\gamma$-нейтронами с флюенсом $10^{15} \mathrm{~cm}^{-2}$ и дозой $10^{7}$ рад: 1 - до облучения, эксперимент; 2 - после облучения, эксперимент; 3 - после облучения, расчет. Указанные уровни облучения набирались за несколько импульсов ядерного реактора. Данные приведены для структуры из группы 3 табл. 1.

облучения. После облучения $n^{-}-n-n^{+}$-GaAs-структуры нейтронами флюенсом $10^{15} \mathrm{~cm}^{-2}$ в слое, примыкающем к металлическому контакту, и в глубине структуры было зафиксировано уменьшение концентрации свободных электронов [5], что в литературе [1,5] традиционно связывают с захватом электронов на генерированные радиацией ловушки, связанные с комплексами радиационных дефектов, включающими доноры. Аномальным является наблюдаемое увеличение концентрации в слое структуры, соответствующем максимуму на зависимости концентрации от координаты. Согласно литературным данным, например [11], концентрация электронов в GaAs при $\gamma$-нейтронном облучении монотонно убывает и может быть описана зависимостью $n=N_{d}\left(1-a F_{n}\right)$, где $n$ - концентрация электронов после облучения, $N_{d}$ - концентрация доноров до облучения, $F_{n}-$ флюенс нейтронов, а параметр $a$ зависит от концентрации донорной примеси. Экспериментально получено, что распределение электронов после облучения не только отличается от предполагаемого по результатам расчетов в 1.5-2 раза, но и увеличивается на границе слоев канал-буферный слой по сравнению с исходным значением [5]. Возможно, указанное аномальное поведение связано со стимулированной радиационным облучением диффузией доноров к границе раздела эпитаксиальных слоев легированного и нелегированного материалов. Ранее указанный эффект наблюдался при ионно-лучевом легировании кремниевых структур [12], но при нейтронном облучении арсенид-галлиевых структур обнаружен впервые. 
Таблица 2. Сравнение характеристик разных групп образцов ПТШ до и после $\gamma$-нейтронного облучения

\begin{tabular}{|c|c|c|c|c|c|c|}
\hline $\begin{array}{l}\text { № группы } \\
\text { образцов }\end{array}$ & $\begin{array}{c}\text { Флюенс, } \\
\times 10^{14} \mathrm{~cm}^{-2}\end{array}$ & $\begin{array}{c}\text { Коэффициент } \\
\text { усиления, дБ (37 ГГц) }\end{array}$ & $\begin{array}{c}\text { Коэффициент } \\
\text { шума }(F), \text { дБ (37 ГГц) }\end{array}$ & $\begin{array}{c}\text { Разброс значений } F \\
\text { в выборке, \% }\end{array}$ & $\begin{array}{c}\text { Напряжение } \\
\text { исток-затвор, В }\end{array}$ & $\begin{array}{l}\text { Рабочий } \\
\text { ток, мА }\end{array}$ \\
\hline \multirow[b]{2}{*}{3} & До & 6 & 3.4 & 35 & -0.24 & 12.9 \\
\hline & 0.2 & $\begin{array}{l}6 \\
6 \\
6\end{array}$ & $\begin{array}{l}4.1 \\
3.6 \\
5.1\end{array}$ & $86(!)$ & $\begin{array}{c}+0.09 \\
0 \\
-0.27\end{array}$ & $\begin{array}{r}12.3 \\
11.6 \\
7.2\end{array}$ \\
\hline \multirow[b]{2}{*}{4} & До & 6 & 3.2 & 29 & -0.3 & 14.2 \\
\hline & 4 & $\begin{array}{c}6 \\
5 \\
1.6\end{array}$ & $\begin{array}{c}4.1 \\
3.4 \\
-\end{array}$ & 27 & $\begin{array}{c}+0.44 \\
0 \\
-0.3\end{array}$ & $\begin{array}{l}9.3 \\
4.5 \\
1.8\end{array}$ \\
\hline \multirow[b]{2}{*}{5} & До & 5.5 & 3.8 & 27 & -0.96 & 13.6 \\
\hline & 4 & $\begin{array}{c}6(!) \\
5.8 \\
1.2\end{array}$ & $\begin{array}{l}5 \\
4.5 \\
-\end{array}$ & $19(!)$ & $\begin{array}{c}+0.07 \\
0 \\
-0.96\end{array}$ & $\begin{array}{r}13.6 \\
12.6 \\
1.6\end{array}$ \\
\hline
\end{tabular}

Примечание. Выбран типичный представитель из каждой группы (по 16 образцов в группе). Номера групп образцов соответствуют номерам из табл. 1.

В табл. 2 представлены экспериментальные параметры полевых транзисторов Шоттки до и спустя 1 месяц (когда спала наведенная активность) после $\gamma$-нейтронного облучения. Все образцы из каждой экспериментальной группы были изготовлены на одной полупроводниковой структуре. Разброс параметров (исходного тока-стока насыщения) объясняется некоторой клиновидностью толщины эпитаксиального слоя структуры, что обусловливало разную толщину и профиль легирования канала. Величина разброса параметров после облучения существенно зависела от технологии изготовления и определялась степенью ее проработанности: 3 группа - экспериментальные образцы, 4 и 5 группы - образцы, изготовленные по отлаженной (серийной) технологии.

На рис. 6 показано поведение типичных представителей групп образцов при увеличении уровня облучения. Важно, что поведение групп существенно отличается неравновесные структуры, полученные по опытной (экспериментальной) технологии имеют низкий уровень радиационной стойкости, хотя параметры транзисторов до облучения вполне приемлемые. Наблюдается некоторое улучшение параметров транзисторов в группе 3 из-за определенной комбинации концентрации доноров в канале, его толщины и длины затвора ПТШ, когда облучение приводит к оптимизации этих параметров при определенном (весьма существенном!) уровне облучения.

Авторами были проведены расчеты изменений коэффициентов передачи и шума НЕМТ на основе InGaAs/AlGaAs и GaN/AlGaN, а также проделан ряд экспериментов [4-7]. Качественно полученные результаты совпадают с данными для ПТШ: у ряда структур типа HEMT наблюдалась деградация параметров при низких уровнях облучения (до $5 \cdot 10^{14} \mathrm{~cm}^{-2}$ ), тогда как для серийных транзисторов отечественного и зарубежного производства уровень отказа превышал $10^{15} \mathrm{~cm}^{-2}$

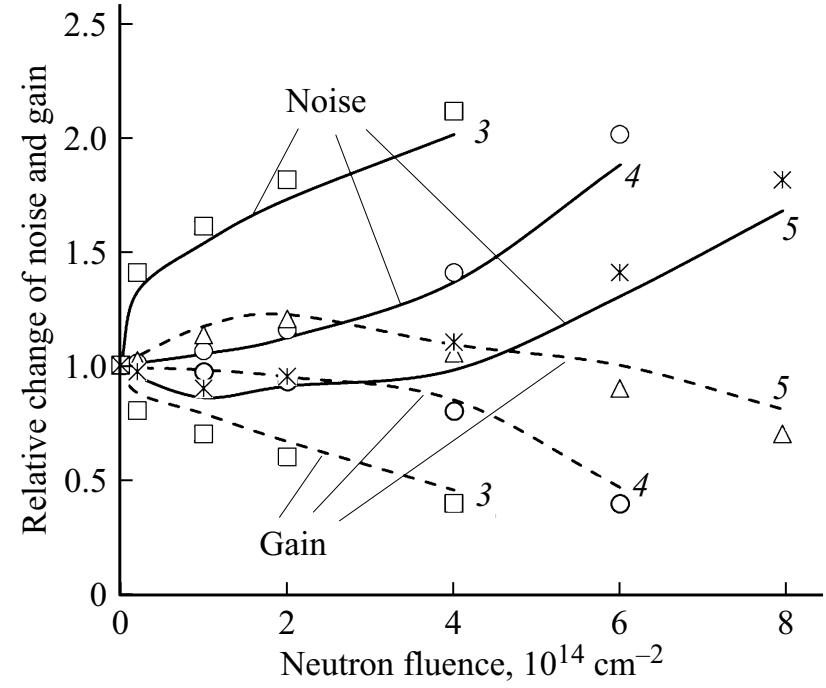

Рис. 6. Зависимость коэффициентов усиления и шума от уровня нейтронного облучения для трех ПТШ из выбранных групп образцов (3,4 и 5 согласно обозначениям табл. 1).

и $10^{7}$ рад. В ряде отечественных НЕМТ структур на основе InGaAs/AlGaAs также наблюдался аномальный рост коэффициента передачи при облучении нейтронами флюенсом $10^{14}-10^{15} \mathrm{~cm}^{-2}$ (см. табл. 1).

Наиболее показательным является сопоставление времен потери работоспособности исследуемых транзисторов, приведенное в табл. 1. Как следует из таблицы, опытные образцы структур значительно сильнее реагируют на радиационное воздействие за счет неравновесных процессов стабилизации технологических и радиационных дефектов в таких структурах. Отлаженный технологический процесс свободен от указанного недо- 
статка, что существенно повышает уровень стойкости полевых транзисторов как классической конструкции, так и на основе гетероструктур типа HEMT.

\section{5. Заключение}

Результаты работы позволяют сделать следующие выводы.

1. Анализ экспериментальных вольт-амперных и вольт-фарадных характеристик структур, а также компьютерное моделирование транспорта электронов в активной области транзисторов показали, что при $\gamma$-нейтронном облучении наблюдается радиационностимулированная диффузия атомов примеси в структуре при высоких флюенсах порядка $10^{15} \mathrm{~cm}^{-2}$, которая в некоторых случаях может существенно изменять уровень радиационной стойкости транзисторов.

2. Анализ результатов экспериментальных исследований, аналитического расчета и численного физикотопологического моделирования показал, что ионизационная реакция структур классических GaAs полевых транзисторов Шоттки, InGaAs/AlGaAs и GaN/AlGaN НЕМТ при импульсных воздействиях $\gamma$ - и $\gamma$-нейтронного излучения определяется процессами объемной ионизационной проводимости подложки и буферного слоя между областями стока и истока и соответствующими шинами металлизации.

3. Сравнение уровня стойкости и нестационарной реакции транзисторных структур на импульсное воздействие показывает, что уровень бессбойной работы HЕMТ может быть на порядок выше, чем у классических полевых транзисторов Шоттки. Например, получено, что частичный отказ GaAs HEMT структур (группы 6-8 табл. 1) наступает при флюенсах нейтронов $10^{14}-5 \cdot 10^{14} \mathrm{~cm}^{-2}$ и дозе $\gamma$-квантов более $10^{6}$ рад, полный - при флюенсе нейтронов $10^{15} \mathrm{~cm}^{-2}$, дозе $10^{7}$ рад. Для GaN HEMT (группа 9) флюенс нейтронного облучения и доза $\gamma$-квантов для частичного отказа будут $10^{15} \mathrm{~cm}^{-2}$ и $10^{7}$ рад соответственно, для зарубежных GaN HEMT (из группы 10) отказ не выявлен. Время потери работоспособности исследованных приборов определяется состоянием границы раздела канал-подложка (буферный слой) и может составлять от нескольких единиц микросекунд до десятков миллисекунд.

Работа выполнена в рамках соглашения о предоставлении субсидии между Министерства образования и науки России и НИЯУ МИФИ № 8.2373.2017/4.6.

\section{Список литературы}

[1] Е.Р. Аствацатурьян, Д.В. Громов, В.М. Ломако. Радиационные эфбекты в приборах и интегральных схемах на арсениде галлия (Минск, Университетское, 1992).

[2] А.В. Моряшин, С.В. Оболенский, М.Ю. Петров, А.В. Якимов. Радиофизика, 50 (2), 147 (2007).

[3] С.В. Оболенский, М.А. Китаев. Письма ЖТФ, 26 (10), 13 (2000).
[4] Е.А. Тарасова, Е.С. Оболенская, А.В. Хананова, С.В. Оболенский, В.Е. Земляков. ФТП, 50 (12), 1599 (2016).

[5] Е.А. Тарасова, А.В. Хананова, С.В. Оболенский, В.Е. Земляков, Ю.М. Свешников. ФТП, 50 (3), 331 (2016).

[6] В.В. Елесин. Микроэлектроника, 43 (2), 133 (2014).

[7] И.О. Метелкин, В.В. Елесин. Электрон. техн. Сер. 2. Полупроводниковые приборы, вып. 2 (241), 10 (2016).

[8] Е.В. Киселева, С.В. Оболенский. Микроэлектроника, $35(5), 371$ (2006).

[9] Е.В. Киселева, С.В. Оболенский. Вестн. ННГУ. Сер. Физика твердого тела, № 1, 20 (2003).

[10] Е.А. Тарасова, Д.С. Демидова, С.В. Оболенский, А.Г. Фефелов, Д.И. Дюков. ФТП, 46 (12), 1587 (2012).

[11] Р. Зулиг. Радиационные эфбекты в ИС на GaAs // Apceнид галлия в микроэлектронике, под ред. Н. Айнспрука, У. Уиссмена (М., Мир, 1988).

[12] А.В. Скупов, С.В. Оболенский. Изв. вузов. Матер. электрон. техн., № 4, 45 (2007).

Редактор А.Н. Смирнов

\section{Analysis of the behavior of nonequilibrium semiconductor structures and microwave transistors at the time and after pulsed gamma and gamma-neutron irradiation}

M.M. Venediktov' ${ }^{1}$, E.A. Tarasova ${ }^{2}$, A.D. Bozhen'kina ${ }^{2}$, S.V. Obolensky ${ }^{2}$, V.V. Elesin ${ }^{3}$, G.V. Chukov ${ }^{3}$, I.O. Metelkin ${ }^{3}$, M.A. Krevskiy ${ }^{4}$, D.I. Dukov ${ }^{4}$, A.G. Fefelov ${ }^{4}$

${ }^{1}$ Federal Research and Production Center

"Y. Sedakov Research Institute of Measuring Systems“, 603137 Nizhny Novgorod, Russia

${ }^{2}$ Lobachevsky State University of Nizhny Novgorod, 603950 Nizhny Novgorod, Russia

${ }^{3}$ National Research Nuclear University „MEPhl“

(Moscow Engineering Physics Institute),

115409 Moscow, Russia

${ }^{4}$ JSC RPE "Salut",

603950 Nizhny Novgorod, Russia

Abstract The paper analyzes the influence of nonequilibrium processes in semiconductor structures under radiation exposure on the characteristics of structures and microwave transistors based on them. Special attention is paid to comparison of parameters of experimental (experimental) and serial structures and transistors on their basis before and after $\gamma$-neutron irradiation. 